\title{
Using Technology-Assisted Education to Further Employee Development
}

\author{
Eugene J. Monaco \\ University at Albany, State University of New York, Albany, NY USA \\ The Research Foundation for SUNY
}

How to cite this paper: Monaco, J. E (2017). Using Technology-Assisted Education to Further Employee Development. The Educational Review, USA, 1(2), 26-33. http://dx.doi.org/10.26855/er.2017.02.002

Corresponding author: Eugene J. Monaco, University at Albany, State University of New York, Albany, NY USA and the Research Foundation for SUNY.

\begin{abstract}
The significance of e-learning and knowledge management in the workplace cannot be overstated. In today's technology-driven working environments the accelerated pace of change is a constant, and organizations are pressed to rapidly train and retrain workers with increasingly limited timelines and resources. Discerning employers have recognized e-learning as a more productive tool. E-learning increases the possibilities for how, where, and when employees can engage in training. Some organizations have been slower to adapt to e-learning as a training option because of costs, technical limitations, and lack of understanding its fundamental advantages. These factors have become less inhibiting as costs of e-learning have decreased and technical expertise has been aided by user-friendly e-learning formats. This paper addresses the significant impact that e-learning is having on workplace education by measuring how traditional classroom training is being enhanced by mediated instruction. Examples of successful e-learning courses including a design model are demonstrated. Program evaluation data presented describes how the change from the traditional classroom model to a mediated delivery model has had a positive impact on employer and employee needs. The opportunity to conduct future research in this area is discussed.
\end{abstract}

\section{Keywords}

E-learning, Distance education, Mediated instruction, Workplace education, Training

\section{Introduction}

In today's technology-driven work environments, change is a constant, and organizations are pressed to train and retrain workers in new technologies, products, and services with increasingly limited time and resources. An additional factor driving rapid-response, just in time training and retraining is the need for organizations to maintain currency of and accessibility to their knowledge bases for all stakeholders in the work environment 24/7. These factors have led organizations to reconsider the most effective way to transmit knowledge and information to its workforce in a timely fashion. As technology has become more prevalent, affordable, and easier to use in the workplace, many organizations have turned to e-learning as an approach to transfer information, knowledge, and skills to its workers.

This paper traces the emergence of e-learning in the workplace from the end of the twentieth century and further demonstrates how it has rapidly become an effective tool for education and training for both the private and public sector workforce in the United States. It additionally illustrates how a university has collaborated with a government agency to successfully deliver e-learning programs reaching thousands of workers. The paper also examines e-learning effectiveness and offers evaluation 
analysis of a specific state government e-learning program. It also outlines additional research that can be conducted to obtain data on the effectiveness of using e-learning for workforce development.

\section{Migration to E-learning in the U.S. Corporate Workplace}

In the U.S. in the early 2000's training by e-learning rapidly expanded as forward-thinking employers discovered technology-assisted training to be an efficient means to meeting their needs. These employers quickly became aware of barriers high cost of developing and purchasing e-learning, lack of time available for employees to participate, and appropriateness of available content. They innovated solutions to the barriers, such as building learning cultures, testing and piloting limited implementations before scaling, communicating value across organizations, and integrating content into their knowledge management systems (Guthrie, 2002).

As more effective software became available to effectively transfer content to e-learning, employers eventually began to realize the benefits of e-learning: increased options for where, when, and how employees engage in training, expanded employee access to learning, and cost savings. For example, IBM reported saving over $\$ 200$ million in 1999 by converting to e-learning, and Ernst and Young reported reducing costs by 35 percent while improving scalability and consistency (Strother, 2002). Forester Research found that companies spread across many locations could make a good business decision by implementing an online learning program to replace face-to-face learning, and for compliance training, desktop skills development, and leadership training, online learning was more flexible, consistent, and repeatable with minimal travel costs (Forster Research, 2009). Further, Forester's findings showed a 69\% ROI for these approaches to employee learning (Forester Research, 2009). These studies reveal compelling reasons to turn to e-learning.

Because of the successes, e-learning continued to grow in U.S. corporations and rapidly gained momentum as a favored choice for employees and employers alike. The Association for Talent Development's (ATD) 2016 State of the Industry Report found that technology-based training accounted for over $41 \%$ of all workplace training offered by organizations in the U.S. (Miller, 2016).

\section{E-learning Migration in the Government Workplace}

At the same time in the U.S, efficient and cost-effective training approaches were needed in the public sector and for similar reasons: increasing demand on and expectations for governments to provide more and better services, introduction and rapid pace of technology in government, and financial constraints. Therefore, governments at the local, state, and national levels followed the corporate lead and turned to online learning as a solution for workplace training.

Similar benefits to those experienced by the private sector made e-learning attractive to government: convenience, standardization of content, self-service delivery, and cost savings. In a knowledge and information society, e-learning has potential to transform how and when employees learn as well as how they effectively transfer learning to performance. Studies conducted by the U.S. Department of Education (2010) and U.S. Army Research Institute for Behavioral and Social Sciences (Sitzmann, Kraiger, Stewart, \& Wisher, 2006) demonstrated that, when compared to classroom delivery, online learning was also more likely to meet instructional objectives and lead to desired learning outcomes.

A case illustrating the migration in the public sector is found in the State of New York. New York's government is a large and complex bureaucracy employing over 159,000 workers who manage the business of the state over some 69 different agencies. This workforce is a diverse blend of education levels, ethnicities, and rural, suburban, and urban populations. Training this workforce to carry out the wide range of duties needed to perform their jobs had been historically complex, challenging, and inconsistent. Therefore, in 2013 when the state embarked on a reorganization to achieve efficiencies, it introduced consolid ations of common functions (New York State Sage Commission, 2013). This reorganization created a condition prime for alter- 
native methods of training as the workforce needed to perform quickly in the new structure to achieve consistency in content and quality

\section{The University as Expert E-learning Resource for Government}

As early as 1998 the university-based continuing professional education program, the Professional Development Program (PDP), Rockefeller College, University at Albany, State University of New York, had begun developing e-learning programs tailored directly to state agency needs. PDP was challenged to get buy-in - they needed to demonstrate that e-learning could be engaging and effective. A project in 2001 gave the opportunity. At the request of the State of Vermont, PDP converted classroom training for food stamp eligibility workers into online delivery. Implementation was so effective that within a single year Vermont went from having one of the highest error rates in the nation to one of the lowest.

This proof of concept led to NYS agencies seeking online training in collaboration with PDP. PDP's curriculum designers authored several interactive e-learning courses, including a series of training modules for the New York State Department of Health's Tobacco Control Program in 2005.

Logically, in 2013 when the NYS government entity responsible for implementing the 2013 reform efforts needed a partner, they turned to PDP to meet the workforce training need. A proposal resulted for PDP to develop current, just-in-time courses for supervisory training and six other cross-functional courses with consistent messaging and information to be delivered across the entire state workforce. The six courses were: (1) Equal Employment Opportunities, (2) Sexual Harassment, (3) Providing Reasonable Workplace Accommodations, (4) Performance Appraisal, (5) Attendance and Leave Benefits, and (6) Knowledge Management.

\section{Standards and Design Strategy for E-learning Courses}

From its early exploration, PDP had addressed the need for e-learning to be more interactive and of consistent quality. They established standards that were accepted by sponsors and the university academicians. In 2012, PDP published the guidelines for best practices in e-learning in its publication, Standards Guide for E-Learning 2012.

The guidelines draw upon design principles for multimedia instruction established through research as integral to success: interactivity, coherence, modality, signaling, personalization, and redundancy (Golas, 2002). The guidelines also draw on the expertise that PDP acquired through its work with government agencies. The guidelines provide standards for authoring well-

Table 1. Course overview.

This course is the first in a planned series on supervision that provides supervisors with an overview of key job responsibilities and resources available to them to help improve job performance.

Target audience: $\quad$ This course is a mandated training for all NYS employees.

Course structure: $\quad$ This course consists of three topics focusing on the definition of sexual harassment, what behav-iors constitute sexual harassment under New York State law, and individual, supervisory, and agency responsibilities for responding when an incident of sexual harassment is discovered.

Course outcomes: $\quad$ This course provides learners with a clear understanding of their rights and responsibilities regarding sexual harassment in the workplace. The anticipated outcome is that sexual har-assment in state agencies will be reduced because learners will better understand which actions and behaviors constitute sexual harassment.

Course objectives: $\quad$ Explain how sexual harassment is a form of employment discrimination.

After completing this course, - Differentiate between appropriate and inappropriate workplace behavior.

learners will be able to: $\quad$ Respond appropriately to sexual harassment they experience or witness in the workplace. 
constructed, user-friendly courses that ensure learners complete a course without experiencing frustration and navigation problems and apply to all courses that PDP develops across a range of content areas.

The design strategy that PDP followed evolved from the Instructional Systems Design (ISD) model in performance-based training (Clark, 2006). The strategy itemized the goals and objectives at the outset, outlines the instructional approach, and provides a basic content outline. The sample course map in Table 1 illustrates this process for a sample course.

\section{Media Integration}

Easy-to-navigate media integration is a key factor for on-line learning success. A course uses images to illustrate activities and to represent terminology and topic icons. Figure 1 illustrates a course home page. This page provides access to each of the topics and resources within the course. All key points are graphically reinforced by the use of interaction icons and scenario-based activities that engage the learner. The media treatment repeats for all course offerings.

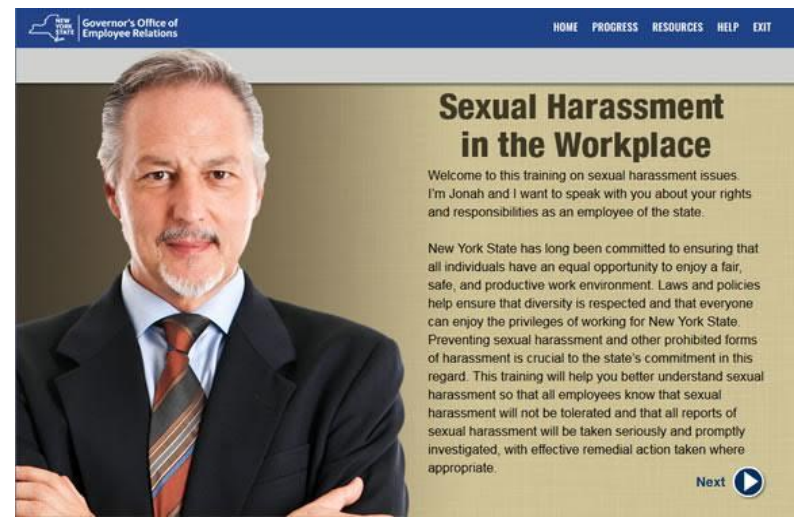

Figure 1. Course home page.

\section{Effectiveness of Online Learning}

Evaluation of online delivery continues to evolve as technology-assisted learning evolves. The report Evaluation of Evidence-Based Practices in Online Learning: A Meta-Analysis and Review of Online Learning Studies (U.S. Department of Education, 2010) differed from prior studies of distance learning in that only web-based learning was included. 45 studies were analyzed across 50 effect sizes. It was found that, on average, students learning online perform modestly better than those receiving face-to-face instruction. Similarly, in a meta-analysis of job-related courses conducted by web-based instruction was found to be somewhat more effective $(6 \%)$ in teaching declarative knowledge than classroom instruction and equally effective in teaching procedural knowledge (Sitzmann et al., 2006). These classroom and online learners reported equal satisfaction with their instructional experiences. Learners who self-selected online learning had better outcomes than learners who were randomly assigned. This is likely a consequence of level of comfort with technology and individual learning style.

A helpful approach to evaluating online learning programs is to measure learning effectiveness (cognitive), learner satisfaction (affective) outcomes and skill based outcomes (Wan, Compeau, \& Haggerty, 2014). The focus of these measurements should be on how to improve courses that in the long run will make a better experience for learners.

Online learning has demonstrated that if used correctly it provides benefits for both learners and employers. Advantages of online learning include consistent delivery of training to all participants, ability to offer just in time training to meet workforce needs and ability to deliver content in a manner that reduces information overload (Guthrie, 2002). 


\section{Evaluation of New York State's E-learning Initiative}

Evaluation of the effectiveness of New York State's e-learning courses for the 2015 initiative indicated outcomes similar to national research findings. Procrastination in on-line courses can be an issue (Elvers, Polzella, \& Graetz, 2003), but this was not found to be the case with the courses offered in this study. Using the course evaluation instruments mandated for state employees, PDP e-learning courses achieved results consistent with the national findings: increased understanding of subject matter and favorable response to online instructional methods.

The data verifies that the majority of participants effectively understood the material and the varied instructional approaches were considered an effective way to present material. Tables 2 and 3 illustrate: Table 2 reports that learners were able to understand the content; Table 3 refers to satisfaction with the instructional methods, such as games, quizzes and case studies.

Table 2. Impact of instruction.

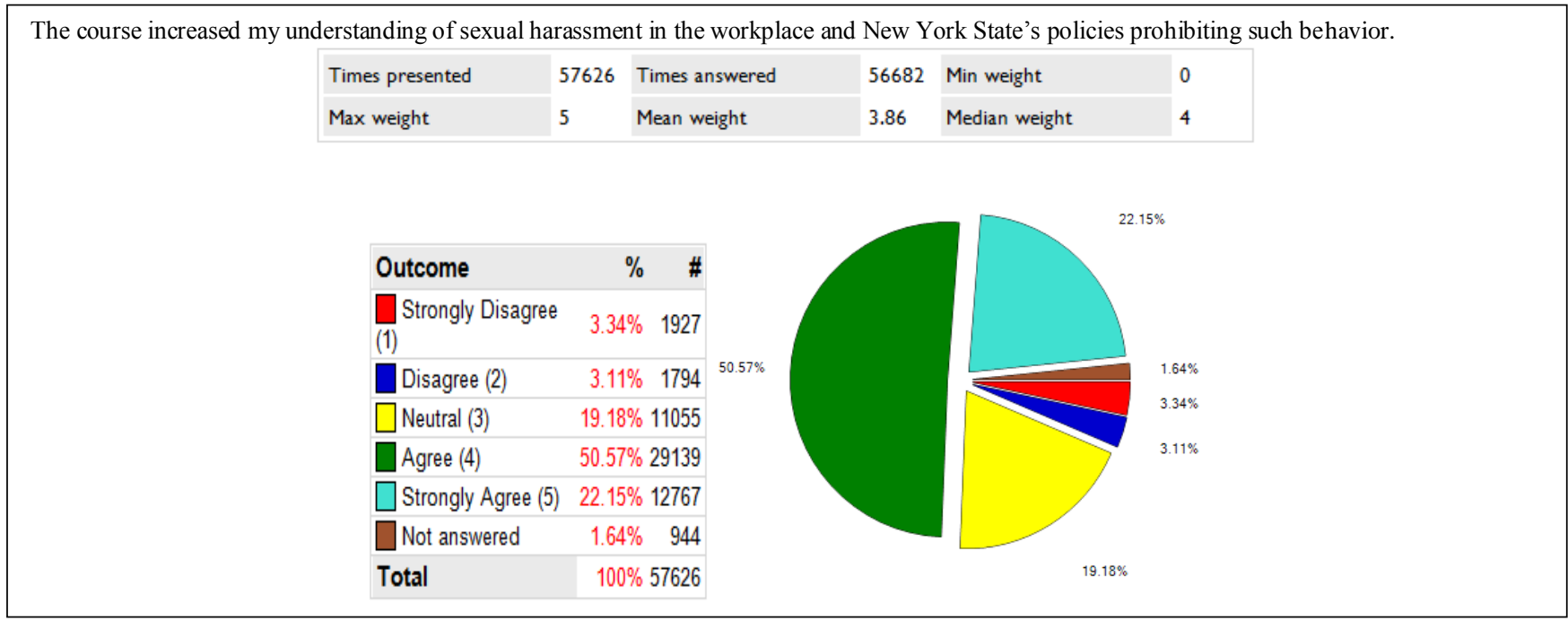

Table 3. Methods of instruction.

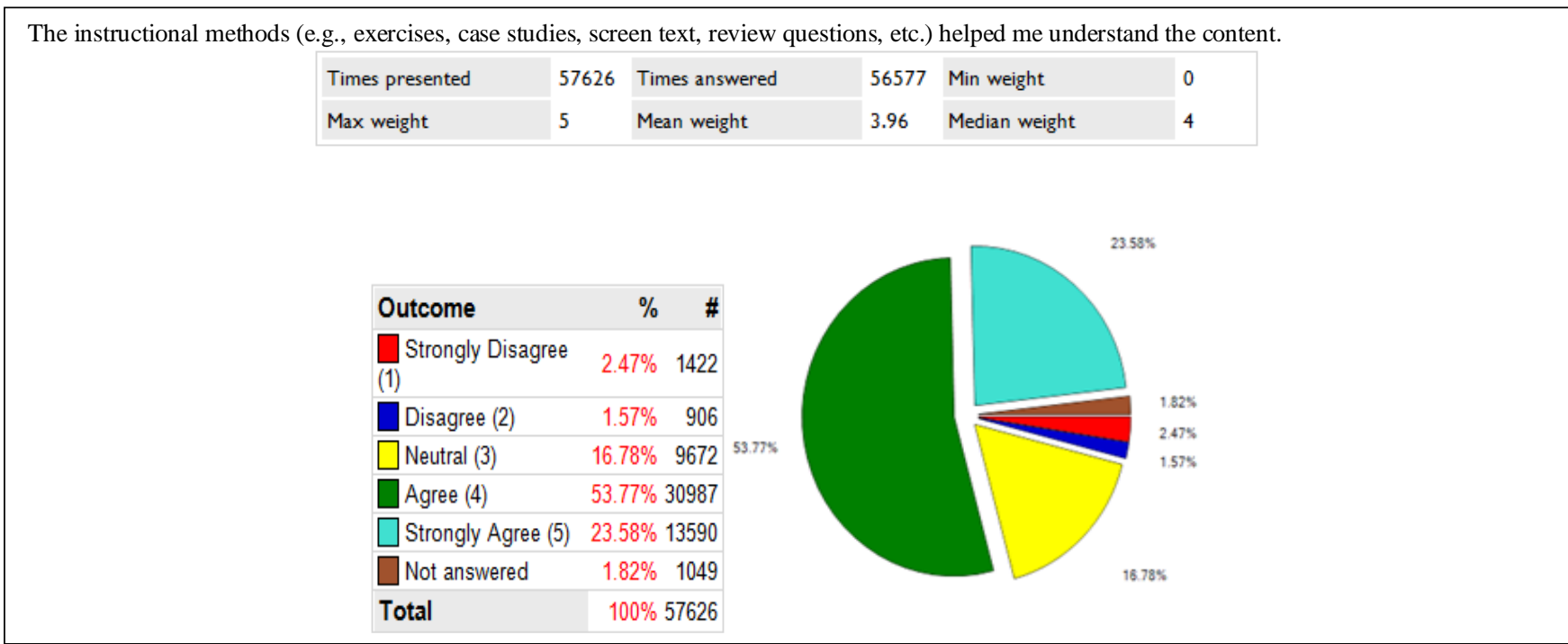




\section{Longitudinal Study}

The creation of the e-learning programs is a direct response to the need for training that will equip state governmental workers with knowledge and competency skills to better perform their job functions. In order to assess if this training has the intended impact, the long term research question is: "Will employees, who complete the training, improve their job skills and use them to make positive progress in their workplace?" To address the research question, a longitudinal design method will be employed to collect data, via an online survey, from the same trainee at three different points, to assess changes in the trainees' knowledge areas and competency skills over time. The time range for data collection points include a baseline measure gathered before the training begins then at 45 and 90 days after the training (Saldivar, 2012).

The online survey will ask trainees to self-assess their proficiency level regarding the training knowledge areas and competency skills. As a pilot study, the evaluation will be conducted with a first cohort of 40 trainees. Since the training will continue to be offered over a five-year period, four additional cohorts of 40 trainees will be a part of the longitudinal study.

The online survey consists of items asking trainees to rate their proficiency of the training areas. For the 45 and 90 -day follow-up online surveys, additional open-ended questions will be incorporated to ask trainees to provide concrete examples of how they successfully applied their newly acquired training knowledge and skills at the workplace.

A content analysis will be conducted to analyze the qualitative open-ended question data. For the quantitative closed-ended proficiency ratings, a Repeated Measures Analysis of Variance (ANOVA) will be used to test if there are significant differences in mean scores (Scheiner \& Gurevitch, 2001). The analyses will include mean score comparisons both within and between each cohort group. The planned statistical analyses will help to provide an answer to the research questioned. The qualitative analyses will complement the quantitative results and provide a more enriched view of the survey results.

\section{Scope of Future Research}

Future research to determine the ongoing effectiveness of online learning is necessary to validate the efficacy of the long-term benefits of using such an approach for workforce training. The additional research based on an evaluation plan that incorporates elements of the longitudinal study such as assessing participants improved knowledge, skills and attitudes, in the areas covered at the completion of the program will provide valuable information for future planning (Hart, 2017).

Forthcoming studies need to quantify if participants find a combination of different online training delivery approaches effective and which approaches best enhanced their learning (Tutty, 2008). Another important element requiring more in depth exploration is to gather data related to knowledge gain and how it is maintained over time. The collection of information from the participants' immediate supervisor is a critical factor in determining this outcome. The analysis of this data will delineate the supervisors' perceived increase in their employees' knowledge and skill areas that were covered in online training programs. One additional study that is important is to discover if there is sufficient evidence, which supports participants having applied the training content to their workplace from both the participants and their immediate supervisors' perspectives (Saldivar, 2012).

If the findings of these various studies are encouraging, this additional research will greatly support outcomes demonstrating the effectiveness of mediated instruction, which can be disseminated with stakeholders to build increased support for future online learning programs for workforce development.

\section{Conclusion}

The 2015 New York State project demonstrates that implementing evidenced based e-learning principles can produce the desired outcomes, and the proof of concept was achieved. The technology-based e-learning program validated that in a government work environment e-learning can be an effective instructional strategy for developing the knowledge, skills, and aptitudes 
workers need in their state agency positions to ensure the information and behaviors required to effectively carry out job duties and responsibilities in a uniform and consistent manner are achieved.

Other research studies done in the private sector have found similar results (Freifeld, 2014). In case studies, Economical Insurance, Jiffy Lube, San Diego Zoo, and Greyhound Lines Inc. found scalable training reduced cost, increased return on investment, resulting in higher retention rates by trainees, and delivered consistent content (Freifeld, 2014).

These studies further support the principles that effective e-learning must consist of the following elements: sustainability, usefulness, and potential to return benefits to organizations as well as learners. To achieve these in an online learning format depends largely on how a course is designed, delivered, and ultimately evaluated. This state program validates these presumptions and acts as a guide to successfully transition a course or program from traditional classroom to an e-learning delivery format. This model also illustrates the way in which a strong collaborative working relationship between higher education and state government will achieve desired outcomes.

Future research identifying appropriate e-learning models that produce the desired outcomes for workforce development will enhance the viability of mediated instruction as a valid approach to conducting training.

\section{References}

Clark, R. (2006). Participant's Manual for How to Plan, Develop, and Evaluate Training. (3rd ed). Cortez, CO: CLARK Training \& Consulting.

Davies, J. \& Graff (2005). Performance in E-learning: Online Participation and Student Grades. British Journal of Educational Technology, 36(4), 657-663.

Elvers, G.C., Polzella, D. J., \& Graetz, K. (2003). Procrastination in Online Courses: Performance and Attitudinal Differences. Teaching of Psychology, 20(2), 159-162.

Forester Research. (2009). The ROI of E-learning: A Total Economic Impact. Accessed December $27,2016$. http://www.elearninglearning.com/html/research/roi/.

Freifeld, L. (2016). Online vs. In-Class Success. Accessed December 27, 2016. https://trainingmag.com.

Golas, K. (2002). Guidelines for Designing Online Learing. Accessed August 8, 2017. http://.tss.swri.org/tsd/publications/2002ITSC_ONLINELEARNING.html.

Guthrie, K. (2002). Barriers to the Adoption of Online Learning in U.S. Higher Education. Educause Review, 47(4), 50-51.

Hart, H. (2017). The Latest on Teaching, Learning and Technology. Accessed August 8, 2017. https://facultyinnovate.utexas.edu/staff.

Hoskins, S. L., \& van Hoof, J. C. (2005). Motivation and Ability: Which Students Use Online Learning and What Influence Does It Have on Their Achievement. British Journal of Educational Technology, 36(2), 177-192.

Miller, L. (2016). 2016 State of the Industry. Alexandria, VA: American Association for Talent Development. Accessed February $29,2016$. https://www.td.org/Professional-Resources/State-Of-The-Industry-Report.

Monaco, E. (2014). Using Technology-Assisted Learning to Transform Employee Development. International Journal for E-Learning Security, 4(1), 366-375.

New York State SAGE Commission. (2013). Redesign of State Government. Albany, NY: Author. Accessed December $27,2016$. https://www.governor.ny.gov/assets/documents/SAGEReport.pdf.

Reeves, T.C., Herrington, J., \& Oliver, R. (2004). A Development Research Agenda for Online Collaborative Learning. Educational Technology, Research and Development, 52(4), 53-65.

Saldivar, M. G. (2012). A Primer on Survey Response Rate. Florida State University: Learning Systems Institute.

Savenye, W. C. (2004). Alternatives for Assessing Learning in Web-Based Distance Learning Courses. Distance Learning, 1(1), $29-35$.

Scheiner, S. M., \& Gurevitch, J. (2001). Design and Analysis of Ecological Experiments. New York: Oxford University Press.

Sitzmann, T., Kraiger, K., Stewart, D., \& Wisher, R. (2006). The Comparative Effectiveness of Web-Based and Classroom Instruction: A Meta-analysis. Personnel Psychology, 59(3), 623-664.

Strother, J. (2002). An assessment of the Effectiveness of E-learning in Corporate Training Programs. The International Review of Research in Open and Distance Learning, 3(1), 1-13.

Tutty, J \& Klein, J. (2008). Computer-Mediated Instruction: A Comparison of Online and Face-to-Face Coloration. Education Tech Research Dev., 56, 101-124. 
U.S. Department of Education. (2010). Evaluation of Evidence-Based Practices in Online Learning: A Meta-analysis and Review of Online Learning Studies. Accessed December 27, 2016. http://www2.ed.gov/rschstat/eval/tech/evidence-based-practices/finalreport.pdf.

Wan, Z., Compeau, D., \& Haggerty, N. (2012). The Effects of Self-regulated Learning Processes on E-learning Outcomes in Organizational Settings. Journal of Management Information Systems, 29(1), 307-340. 